\title{
Public preferences for green infrastructure improvements in Northern New Jersey: a discrete choice experiment approach
}

\author{
Taylor Wieczerak $^{1,3}$ D Pankaj Lal ${ }^{1} \cdot$ Benjamin Witherell ${ }^{2} \cdot$ Sydney Oluoch ${ }^{1}$
}

Received: 9 July 2021 / Accepted: 10 January 2022 / Published online: 27 January 2022

(c) The Author(s), under exclusive licence to Springer Nature Switzerland AG 2022

\begin{abstract}
Significant water pollution caused by flooding due to heavy precipitation and extreme weather events has become a considerable problem in urbanized areas such as in Northern New Jersey. These cities experience heavy downpour-related contamination and water pollution when stormwater and untreated sewage are diverted through combined sewer overflow drainage systems to adjacent water bodies. Green infrastructure has proven a successful intervention method for mitigating these unintended environmental consequences. However, while the effects of CSOs and the ability of GI to reduce them are well documented, there has been considerably less study addressing public preferences and willingness to pay for GI-based solutions. As such, this study seeks to understand these facets of GI management in urbanized areas of New Jersey, focusing on Newark, Paterson, and Elizabeth townships. A discrete choice experiment method was used to analyze the willingness of residents to pay for additional CSO infrastructure through the installation of GI options such as bioretention gardens, rain barrels, and green roofs. Furthermore, study identified attributes such as secondary benefits, proximity, and water retention that respondents found the most utility in when choosing GI stormwater management interventions. We found that several attributes, including improved air quality $(\$ 58.60)$, increased water supply (\$49.71), and closer proximity (\$110.01-\$125.97) had the highest utility and similarly were associated with a higher willingness to pay than other tested attributes. These findings are important in assessing the overall attitude toward these fixtures, and may be critical in crafting local policy and development, especially to address environmental equity.
\end{abstract}

Keywords Stormwater management · Combined sewer overflow · Green infrastructure $\cdot$ Discrete choice experiment $\cdot$ Willingness to pay

Taylor Wieczerak

wieczerakt1@montclair.edu

Extended author information available on the last page of the article 


\section{Introduction}

As a result of dense urbanization over decades, northern New Jersey towns and cities are exposed to significant risk from high precipitation and flooding events. These hydrologic events can have significant adverse effects for both human and environmental health (Soriano and Rubio 2019). Combined sewer overflow (CSO) infrastructure is one of the most critical water quality issues facing coastal and river communities; limited control of CSOs is one of the foremost problems leading to surface water impairment in urban environments (Soriano and Rubio 2019; Fu et al. 2019). CSOs are common in the Northeastern United States, and are considered public health risks as a result of discharge containing domestic, commercial, industrial, and stormwater pollution, especially when exacerbated by the growth of impermeable surfaces that characterize urbanization (Chen et al. 2019; Fu et al. 2019). This infrastructure largely represents an aging fixture for stormwater management in older urban areas across the United States, and has come under increased scrutiny in recent years for its potentially harmful effects on the environment and human health (NJDEP 2019).

Combined sewer systems are characterized by a design of sewer infrastructure that uses a common pipe in order to transport sewer water, such as sewage and other residential waste, along with runoff and waste water, to its destination at a water treatment plant. Under normal circumstances, runoff stormwater will travel from the street level down into this combined pipe, keeping this water separate until treatment. However, this combined design can fail during rain events with high runoff; too much water entering the pipes may overwhelm the system, and the wastewater will then be discharged. Urban areas, which are characterized by a high percentage of impervious surfaces, contribute to this problem, and rainfall events that are not particularly significant may still cause CSOs to be overwhelmed. (NJDEP 2019, Salerno et al. 2018). Changing water dynamics and other uncertainties caused by global climate change have given these issues more urgency, as increased discharge from CSOs brought on by rising water levels or increased storm frequency or strength could make contamination more common (Jagai et al. 2015; Li et al. 2019). Further, these events exacerbate existing problems with increasing flooding, including threats to public infrastructure, urban networks, resident health, and property, especially for vulnerable populations (Venkataramanan et al. 2020).

The socio-economic aspects of stormwater management options (especially aging solutions such as CSOs) are not well understood and rarely reported in the literature, or integrated with more common physical and technological solutions. A better understanding of the socio-economic features of stormwater problems is needed to develop successful design and public policy solutions (Jayasooriya and $\mathrm{Ng} \mathrm{2014).}$ In the wake of large storms such as Hurricane Sandy, there has been heightened perception of the problems presented by continued use of CSO infrastructure, and efforts by the New Jersey Department of Environmental Protection (NJDEP) and the United States Environmental Protection Agency (USEPA) to mitigate CSO discharges are improving (NJDEP 2019). While several technical solutions for CSO mitigation exist, including improved gray infrastructure and different GI solutions, 
there is limited understanding of the public perception and comprehension of the economic and environmental tradeoffs of these solutions, particularly regarding GI (Jayasooriya and Ng 2014; Tsihrintzis and Hamid 1997). As such, this study proposes to bridge this research gap by studying the socio-economic aspects of stormwater management and assessing public perceptions to ultimately improve management decision making for public officials.

While the costs and benefits of gray infrastructure have a broad base of understanding and standardized methods of valuation, green infrastructure (GI) options are less understood (Bowen and Lynch 2017). GI can necessitate considerable public investment in terms of both private property and capital, which creates a need for better understanding (Bowen and Lynch 2017; Nordman et al. 2018). Public willingness to pay analyses for different GI options may be able to help identify the best approach to improve public participation in investing, managing, and overall taking a more active role in stormwater management strategies. This may be able to not only help allocate resources more effectively, but also add resources in the form of social capital. The results of this study will be of interest to government agencies, city planners, and environmental managers, may help to fill in gaps in the current research, and also create a more complete picture of the socio-economic structure behind management decisions.

\section{Literature review}

\section{Human and environmental health of CSOs}

CSOs create a significant problem for both human and environmental health, and their effects have been well documented by scientific literature (NJDEP 2019; Soriano and Rubio 2019; Salerno et al. 2018; Fu et al. 2019). CSOs, when they discharge, can put significant amounts of environmental, chemical, and anthropogenic wastes and hazards into waterways; the USEPA estimates that over 23 billion gallons of untreated sewage may be discharged into North Jersey waters due to CSO failures annually (EPA 2012).

During a discharge event, untreated sewage is the biggest cause of concern for human health as it includes microbial pathogens, viruses, and protozoa, which are all linked to illness in humans; high concentrations of fecal coliforms and other dangerous microbes as a result of CSO discharge have been tied to waterborne disease outbreaks in the United States and abroad, such as in Milwaukee, Cincinnati, New York, and Tokyo (Donovan et al. 2006; Brokamp et al. 2017; Jagai et al. 2015; Shibata et al. 2014). Though drinking water contamination presents the most serious risks to human health, CSO contamination can also be dangerous even in cases that do not involve ingestion. The EPA estimates that between 1.8 and 3.5 million people become ill due to recreational contact with water contaminated by sewer outfalls (Veronesi et al. 2013). CSOs also contribute to pollution through the collected storm runoff being discharged into the stream, as it may contain chemicals, fertilizers, and other pollutants that can cause environmental damage such as significant decreases 
in dissolved oxygen and toxic exposure (Varonesi et al. 2013; Soriano and Rubio 2019).

To further exacerbate these issues, CSOs can be relatively easily overwhelmed, as some urban areas of New Jersey can face discharge events with as little as one inch of rainfall (Battelle 2005; Donovan et al. 2006). These mild events, though not to the scale that larger storms such as Irene or Sandy, can still trigger stormwater discharge that is sufficient to cause significant waterway contamination or toxicity, especially near the discharge site (Casadio et al. 2010; Sandoval et al. 2013).

\section{Green infrastructure as a mitigation option}

GI refers to source control measures that reduce stormwater flow by promoting infiltration, evapotranspiration, and the capture and reuse of rainwater (de Sousa et al. 2012). GI can be in different forms, including green roofs, rain gardens, biofiltration basins, and permeable pavement, all of which act in varying capacity to reduce the overall amount of impervious surface area (USEPA 2013). Reducing impermeable area can reduce stormwater runoff and delay infiltration, which can reduce flooding and the negative effects caused by it (Li et al. 2019). GI's adaptability facilitates its use in a number of settings, including in areas that traditional gray infrastructure options generally has difficulty utilizing effectively, such as rooftops (USEPA 2013; Li et al. 2019). Though the increased infiltration of stormwater is one of the primary draws of GI options, these also have a host of other benefits, both for sustainability and more generally. Studies have found that different kinds of GI can remove pollutants from water, enhance carbon sequestration, reduce the urban heat island effect, improve air quality, increase drought resilience, control temperature, and improve esthetics and real estate value, among other benefits (Abhijith et al. 2017; Cohen et al. 2012; De Sousa et al. 2014; Li et al. 2019; Venkataramanan et al. 2019; Venkataramanan et al. 2020; Zhang and Chui 2019). Though gray infrastructure can present a more effective solution in terms of flooding risk, the use of GI can avoid some of its shortcomings, including increasing non-point source pollution, water quality deterioration, groundwater shortage, and changes in air temperature, humidity, and evapotranspiration (Zhang and Chui 2019).

Cities around the United States and abroad have begun to make GI a part of their plans for stormwater management, including Philadelphia, New York, Kansas City, and Chicago (De Sousa et al. 2014; Cohen et al. 2012). Philadelphia, for example, relies heavily on GI installations around the municipality to incrementally reduce discharges while providing significant benefit to its economy (Econsult 2016; Philadelphia Water Department 2017a, b). Studies suggest that GI can work as a costeffective solution, especially in comparison to traditionally used gray infrastructure (USEPA 2007; USEPA 2013; Auckland Regional Council 2009; Li et al. 2019; Nordan et al. 2018). Cohen et al. (2012) used the study area in Turkey Creek, Kansas to model and compare the prices of GI as compared to gray infrastructure alternatives. They found that applying rain gardens to augment some gray infrastructure improvements rather than use gray infrastructure exclusively could save between $\$ 22$ and $\$ 35$ million for this CSO drainage area, and significantly reduce the amount of storm 
runoff to force CSO discharge. Thus, as both a cost-saving and effective measure against CSOs and increasing storm runoff in general, GI has become a staple in many areas worldwide. However, despite these quantified benefits, the adoption of GI has been relatively slow (Bowen and Lynch 2017).

\section{Public perception regarding green infrastructure}

While GI is growing in popularity and has been used effectively, it remains a relatively new solution compared to traditional gray infrastructure, and therefore research gaps exist in areas such as pricing and public perception. Thus, the body of literature on areas such as social perception (specifically with discrete choice experiment) is not yet comprehensive, though there have been some studies that have explored this facet of GI. Veronsei et al. (2013) utilized a discrete choice experiment on a local population in Switzerland to understand their willingness to pay to reduce the negative effects of CSOs, and what factors affected their willingness. They found that most of the selected sample was willing to pay higher taxes to reduce this risk, largely to protect water bodies and prevent environmental and human health risks. Meng and Hsu (2019) explored the use of GI in public municipalities with public officials as respondents. They found that public agencies are willing to pay more for smart GI with lower maintenance and operating costs over time, and that agencies that had utilized GI previously were more likely to do so again with smart infrastructure. Shr et al. (2019) used choice experiment approach to understand how visual aids affected respondent perception of GI, and found more favorable results from surveys that included images. Halkos and Matsiori (2012) used contingent valuation to understand willingness to pay and desired attributes for coastal zone quality improvements, and concluded that previous environmental behavior was critical in predicting willingness to pay.

This study applied a discrete choice experiment methodology to GI in the general public to reveal new insights on perceptions and willingness to pay. This built on existing literature by using discrete choice experiment and willingness to pay to understand public preferences for GI. Such a study will not only be able to inform city planning and management for GI projects, but may be able to suggest effective ways to move forward with stormwater management (particularly in mitigating CSOs) with more public support. To our knowledge, no such study has been carried out in New Jersey, which may be a critical area due to the confluence of urban and coastal climate change challenges it faces.

\section{Methodology}

\section{Study area}

New Jersey is home to a significant number of CSO sites, particularly in the industrialized and urbanized areas in the northern part of the state. The Newark Bay and the Lower Passaic region of New Jersey are noted for the considerable pollution 
and contamination of water bodies, largely as a result of historical and continuing industrialization, manufacturing, and urbanization. Several water bodies, including the Passaic River, flow through this densely populated area. Nearly 40 CSO outlets discharge into the Newark Bay/Kill van Kull area, and another 22 discharge into other waterways in this region. This area has several of the factors that put it at risk for high frequency and volume of CSO discharge events, notably a significant area of impervious surface. In the wake of Hurricane Sandy, in which large amounts of discharge contamination were released into local waterways, the state administration took steps to improve the resilience of areas that will be at risk during future extreme weather events (NJDEP 2015).

Newark, Elizabeth, and Paterson are cities within this area that have some of the highest numbers of outfalls in the state, with 17, 28, and 24 outfalls, respectively (NJDEP 2019). All three cities are among the highest population centers in New Jersey for both population and population density, which exacerbates the health issues that CSOs present. Because CSO discharges are strongly affected by stormwater runoff due to impervious urban surfaces, these cities serve well as examples for areas vulnerable to worsening consequences of using CSOs. Further, these areas have high rates of poverty, low college graduation rates, and high minority populations, which can make these areas of note for environmental justice concerns (US Census Bureau 2020). The most recent census estimates for these areas are summarized in Table 1.

\section{Discrete choice experiment}

A discrete choice experiment (DCE) approach can help understand consumer preferences for products or services that do not have a traditional market. This technique presents respondents with a number of different alternatives with varying attribute levels in order to understand which choices are favored over the others. An analysis of the resulting choices can then be used to allow for an estimation of the overall value of each attribute, and can identify both significance of attributes and how individuals are willing to trade attributes (Meng and Hsu 2019; Mangham et al. 2008). This method can also estimate the willingness to pay (WTP) for unit changes in the various attributes, which can be useful in management and planning scenarios (Mangham et al. 2008).

DCEs are grounded in random utility theory, which posits that the utility an individual derives from a good is dependent on the characteristics of a good and its unobserved components (McFadden et al. 1973). When stating their preference in their choice, it is assumed that respondents choose the alternative that yields the highest individual benefit (or utility), which in turn results from the combination of various attributes and attribute levels (Lancaster 1976; Mangham et al. 2008).

In general, a respondent $q$ 's utility from choosing alternative $j$ in choice situation $t$ in a utility function with random parameters can be defined as

$$
U j t q=V j t q+\varepsilon j t q=\beta^{\prime} q k X j t q k+\varepsilon j t q
$$


Table 1 Census and EPA population and demographic statistics for study areas

\begin{tabular}{|c|c|c|c|}
\hline & Newark & Elizabeth & Paterson \\
\hline Population & 280,463 & 128,153 & 145,800 \\
\hline Number of CSO outfalls & 17 & 28 & 24 \\
\hline Poverty rate & $28 \%$ & $18.4 \%$ & $28.1 \%$ \\
\hline Demographics & $\begin{array}{l}\text { White alone } 26.1 \% \\
\text { Black or African Amer- } \\
\text { ican alone } 49.7 \% \\
\text { American Indian and } \\
\text { Alaska Native alone } \\
0.5 \% \\
\text { Asian alone } 2.1 \% \\
\text { Hawaiian or Other } \\
\text { Pacific Islander alone } \\
0 \% \\
\text { Some other race alone } \\
19.1 \% \\
\text { Two or more races } 2.4 \%\end{array}$ & $\begin{array}{l}\text { White alone } 45 \% \\
\text { Black or African Amer- } \\
\text { ican alone } 18.6 \% \\
\text { American Indian and } \\
\text { Alaska Native alone } \\
0.5 \% \\
\text { Asian alone } 2.0 \% \\
\text { Hawaiian or Other } \\
\text { Pacific Islander alone } \\
0 \% \\
\text { Some other race alone } \\
30.2 \% \\
\text { Two or more races } 3.7 \%\end{array}$ & $\begin{array}{l}\text { White alone } \\
29.3 \% \\
\text { Black or Afri- } \\
\text { can American } \\
\text { alone } 26.5 \% \\
\text { American } \\
\text { Indian and } \\
\text { Alaska Native } \\
\text { alone } 0.1 \% \\
\text { Asian alone } \\
3.8 \% \\
\text { Hawaiian or } \\
\text { Other Pacific } \\
\text { Islander alone } \\
0 \% \\
\text { Some other race } \\
\text { alone } 35.6 \% \\
\text { Two or more } \\
\text { races } 4.7 \%\end{array}$ \\
\hline College education & $\begin{array}{l}\text { Associate's Degree } \\
5.5 \% \\
\text { Bachelor's Degree } \\
10.4 \% \\
\text { Graduate or profes- } \\
\text { sional degree } 4.4 \%\end{array}$ & $\begin{array}{l}\text { Associate's Degree } \\
4.5 \% \\
\text { Bachelor's Degree } 9.3 \% \\
\text { Graduate or profes- } \\
\text { sional degree } 3.9 \%\end{array}$ & $\begin{array}{l}\text { Associate's } \\
\text { Degree } 3.4 \% \\
\text { Bachelor's } \\
\text { Degree } 8.4 \% \\
\text { Graduate or } \\
\text { professional } \\
\text { degree } 2.4 \%\end{array}$ \\
\hline Median household income & $\$ 35,181$ & $\$ 46,975$ & $\$ 39,282$ \\
\hline
\end{tabular}

2018 American Community Survey 5-Year Estimates via data.census.gov (US Census Bureau 2020)

where respondent $q(q=1, \ldots Q)$ obtains utility $\mathrm{U}$ from choosing alternative $j$ (Option A, B or C) in each of the choice sets $\mathrm{t}(t=1, \ldots 0.6)$. The utility has a nonrandom component $(V)$ and a stochastic term $(\varepsilon)$. The non-random component is assumed to be a function of the vector $k$ of choice specific attributes: $X_{j t q k}$, with corresponding parameters $\beta_{q k}$ which may vary randomly with a mean $\beta_{k}$ and standard deviation $\delta_{k}$. The utility function of the model with the error term $\varepsilon_{j t q}$ that includes the alternative specific constant representing a dummy for respondent choosing the status quo, can be expressed as a linear function of an attribute vector $(X 1, X 2, X 3$, $X 4)=($ secondary benefit, proximity, reduced flooding, payment $)$.

$$
V j q=A S C q+\beta 1 X 1 q j+\beta 2 X 2, q j+\beta 3 X 3, q j+\beta 4 X 4, q j
$$

The probability that an individual $\mathrm{q}$ will choose alternative $\mathrm{i}$ over any other alternative $\mathrm{j}$ belonging to some choice set $\mathrm{t}$ of: 


$$
\operatorname{Prob}_{i q}=\operatorname{Prob}\left(V_{i q}+\varepsilon_{i q}>V_{j q}+\varepsilon_{j q}\right) \quad \forall j \in \mathrm{t}
$$

Which equals

$$
=\operatorname{Prob}\{(\operatorname{Vin}-\operatorname{Vjn})>(\text { Ejn-Ein })\}
$$

To empirically estimate the observable parameters of the utility function (3), this study assumed that the stochastic components are independently and identically distributed (IID) with a Gumbel or Weibull distribution. This leads to the use of multinomial/conditional logit (MNL) which assumes that unobserved factors affecting the choice of alternatives are strictly independent of each other (Independence of Irrelevant Alternatives, IIA). Hence determines the probabilities of choosing $i$ over $j$ options.

$$
\operatorname{Probin}=\exp (\mu V i q) / \sum j \exp (\mu V j q) \forall j \in t
$$

The willingness to pay (WTP) is the amount a consumer will accept to keep a utility unchanged for a change in attribute (Heng et al. 2020). Hence, the marginal WTP between any attributes and a cost attribute is obtainable.

$$
W T P=(\beta a / \beta \operatorname{cost})
$$

\section{Attributes and optimal choice profiles}

We considered choice experiment literature, GI literature, and previously run studies in the area to determine attributes and their corresponding levels (Veronsei et al. 2013; Meng and Hsu 2019; Shr et al. 2019; Halkos and Matsiori 2012; USEPA 2007). In our analyses, we decided on a total of four attributes, as described in Table 2. Since GI has varied benefits depending on its form, secondary benefits (secondary to its flood mitigation uses) are critical to their utility.

Table 2 Choice set attributes and levels

\begin{tabular}{lll}
\hline & Description & Levels \\
\hline Secondary benefits & $\begin{array}{c}\text { The main benefit that the GI option offers besides its } \\
\text { water retention/flood mitigation functions }\end{array}$ & $\begin{array}{l}\bullet \text { Increased water supply } \\
\text { - Noise reduction }\end{array}$ \\
& & $\bullet$ Habitat creation \\
& & $\bullet$ Improved air quality \\
Proximity & How close the GI would be to a respondent's residence & $\bullet$ On personal property \\
& & $\bullet$ Within a block \\
Reduced flooding & The effect of the GI on local flooding in general terms & $\bullet$ Within the watershed \\
& & $\bullet$ High \\
Payment & How much the respondent would be willing to pay for \\
the GI package in question as a one-time payment & $\bullet \$ 25$ \\
& & $\bullet \$ 50$
\end{tabular}


To this end, we included some of the more common and more easily recognized benefits of GI, including increased water supply, noise reduction, habitat creation, improved air quality, and reduced energy use. Not in my backyard (NIMBY) has become a common problem with gray infrastructure, wherein residents desire the benefits from the fixture, but do not want it in close proximity to them. To delineate this impact, we included several levels of proximity, including on the property, within a city block, or within the watershed. Though GI may not be subject to the same NIMBYism considering its generally more natural forms, this is a critical measurement for perception, and may have significant influence in how municipalities may address proliferation in the future. In our study, more general values for flood mitigation amounts (high and low), could be more effective given that past studies have shown that the general populace may be unfamiliar with flooding dynamics and prevention methods (Shandas 2015; Barnhill and Smardon 2012). Finally, payment levels were developed from pre-test surveys studies in the area, as respondents reacted favorably to them and we received a higher percentage of completed responses as a result. We conducted a pilot survey as pre-test and included an open-ended response for willingness to pay. Respondents were asked to give a realistic amount that they would be willing to pay for GI improvements. These pre-test values were used to determine four equidistant bid amounts for the final survey.

The associated attribute levels resulted in 120 possible profiles $(5 \times 3 \times 2 \times 4)$. We applied a D-efficient combination accounting for orthogonality, level balance, and minimum overlap using the software R. The resulting fractional factorial design of 60 choice set profiles were randomly paired to create 30 choice set cards. These presented two distinct GI projects along with a status quo option for no GI intervention. Using this design, each respondent was given five choice tasks. A sample choice card is included in Fig. 1.

SAMPLE CHOICE CARD

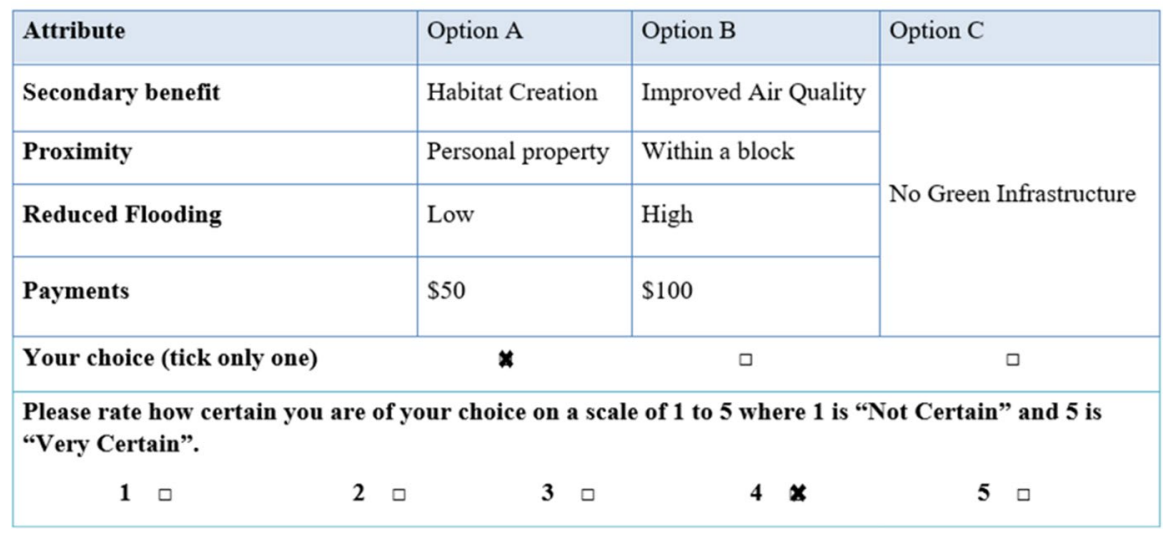

Fig. 1 Sample choice card for choice experiment segment 


\section{Survey design, distribution, and analysis}

The survey was developed using an extensive literature review, and was pretested in summer $2016(n=123)$ to improve comprehensiveness and understandability in Elizabeth, NJ. The pre-test survey introduced the topic of GI with a brief explanation of GI and its potential benefits, including a brief infographic describing some common GI types (permeable pavement, rain cisterns, etc.). Questions in the survey asked for a variety of information from the respondents, including perceptions of stormwater dynamics, the behavior and dangers of stormwater in their area, and how they had personally been affected by flooding or other stormwater event in the past.

The improved survey used questions from the earlier pre-test version, and was expanded to include the discrete choice experiment question. This improved version excluded any questions from the earlier version that did not adequately contribute to GI understanding, or that appeared to have comprehension issues. The improved survey was again pre-tested via Qualtrics random sampling, which was refined to arrive at the final survey. The survey began with Likert scale questions to understand their perceptions on GI, current gray infrastructure, flooding in their area, and their health and safety. Respondents were then presented with choice experiment sets, wherein they were asked to choose between three options to showcase their preferences for various GI attributes. Finally, respondents were asked questions regarding their socio-demographic background information.

Surveys were distributed online via Qualtrics, a third-party polling company, between March and May 2020; surveys were delivered via an email link and respondents were compensated with a small undisclosed reward. In order to ensure a non-biased, representative sample of the cities targeted for the study, surveys were distributed only to residents living in those zip codes. The targeted respondents needed only to be residents of the targeted study areas, and were not chosen for any specific expertise. In total, we received 471 complete responses, including 226 in Newark, 110 in Elizabeth, and 135 in Paterson. These responses were imported into the analytics software STATA $15 \mathrm{E}$ for analysis.

\section{Results and discussion}

\section{Demographic results and goodness of fit}

Our survey received 471 total responses throughout the three cities in the study area. Before moving on to the choice experiment analysis, we used a Pearson $\chi^{2}$ test to understand if our sample was a reasonable representation of the areas in question and New Jersey as a whole. Most of our socio-demographic characteristics had equal means at the $1 \%$ level, indicating a goodness of fit. At a $1 \%$ significance level, the evidence for rejection of the null hypotheses of the equality of means was found for annual household income only. This information is detailed in Table 3. 


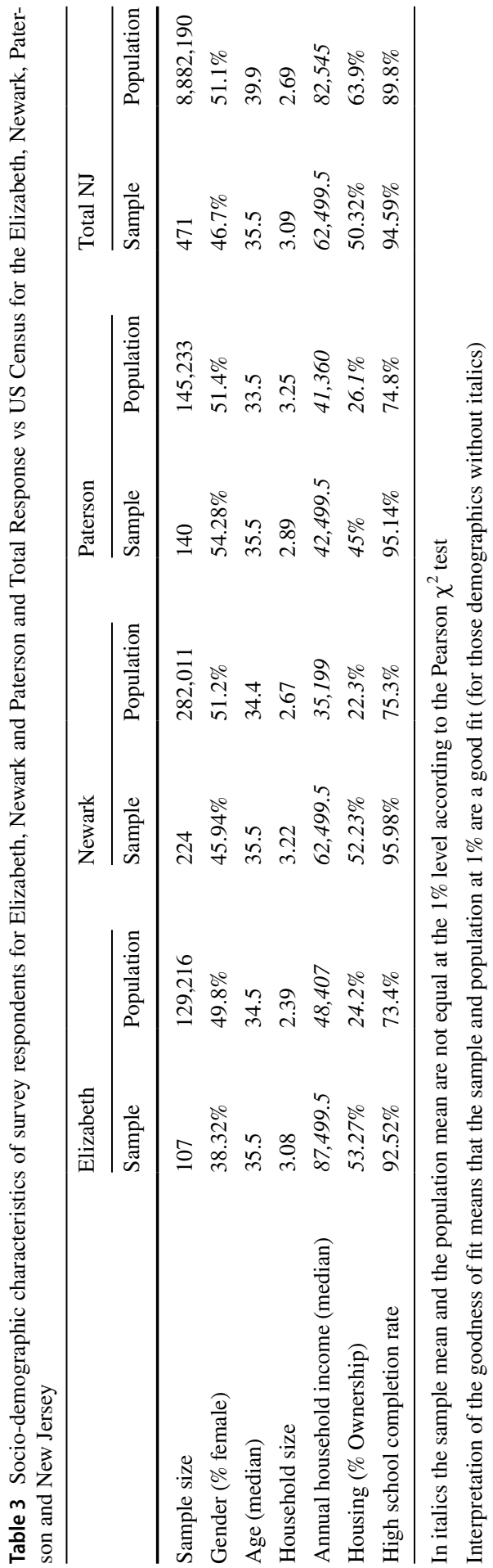




\section{Choice experiment analysis}

Following the procedure for choice experiment evaluation, we ran a conditional logit regression (MNL) in STATA. In order to avoid a saturated model, we considered the attribute levels with the lowest utility to be the baseline that was dropped and considered the reference case; this in line with the choice experiment criteria we utilized. The baseline attribute for secondary benefits was noise reduction, for proximity we considered within a watershed, and for reduced flooding the baseline level was low. Further, we applied interaction factors such gender, education and income on the attributes levels within a watershed and personal property to further delineate factors that may influence respondents' preferences. Because these areas are notable for lower levels of education and income, we felt that interactions with these attributes could make for interesting interaction. Gender, though not particularly notable in the demographic sense, is nevertheless an important attribute that we wanted to explore, as it has implications for targeted outreach as GI initiatives move forward. These results can be found in Table 4 .

Table 4 Conditional logistic regression (MNL) of choice experiment

\begin{tabular}{|c|c|c|c|}
\hline \multirow[t]{2}{*}{ Attribute levels and interactions } & \multicolumn{3}{|c|}{ Conditional logit } \\
\hline & Estimate & $P>|z|$ & Robust std error \\
\hline \multicolumn{4}{|l|}{ Secondary benefit } \\
\hline Improved air quality & 0.254 & $0.005^{* * *}$ & 0.090 \\
\hline Increased water supply & 0.208 & $0.016^{* *}$ & 0.085 \\
\hline Habitat creation & 0.0415 & 0.661 & 0.094 \\
\hline Reduced energy use & 0.0544 & 0.539 & 0.088 \\
\hline \multicolumn{4}{|l|}{ Proximity } \\
\hline Personal property & 0.348 & $0.007^{* * *}$ & 0.128 \\
\hline Within a block & 0.217 & $0.074^{*}$ & 0.121 \\
\hline \multicolumn{4}{|l|}{ Reduced flooding } \\
\hline High & 0.366 & $0.000^{* * *}$ & 0.046 \\
\hline Cost & -0.004 & $0.000^{* * *}$ & 0.0009 \\
\hline$A S C$ & -0.794 & $0.000^{* * * *}$ & 0.168 \\
\hline \multicolumn{4}{|l|}{ Interactions } \\
\hline Within watershed $\times$ gender & -0.399 & $0.000^{* * *}$ & 0.109 \\
\hline Personal property $\times$ gender & -0.389 & $0.000^{* * * *}$ & 0.105 \\
\hline Personal property $\times$ education & -0.204 & $0.078^{*}$ & 0.116 \\
\hline Within watershed $\times$ income & $3.74 \mathrm{e}-06$ & $0.000^{* * *}$ & $9.25 \mathrm{e}-07$ \\
\hline Pseudo $\mathrm{R}^{2}$ & 0.1053 & & \\
\hline Wald $\operatorname{chi}^{2}(13)$ & 547.13 & & \\
\hline Prob $>\mathrm{Chi}^{2}$ & 0.000 & & \\
\hline Log pseudolikelihood & -2657.8879 & & \\
\hline No of observations & 1006 & & \\
\hline
\end{tabular}

$*^{* * *},{ }^{* *}$, and ${ }^{*}$ indicate statistical significance at the $1 \%, 5 \%$ and $10 \%$ levels, respectively 
We received 471 responses, each with several choice experiment sets, giving us an overall total of 1006 observations. The $\mathrm{R}^{2}$ value of 0.1053 indicates a goodness of fit for the model, and suggests that the model provides good parameter estimates. The regression reveals that a number of the choices in the choice sets were significant, including air quality, GI on personal property, high water retention, cost, and increased water supply and GI within a block, albeit at higher levels of significance (0.95 and 0.90 , respectively). Further, interactions between proximity (within the watershed and on personal property) and gender and proximity (within watershed) and income were also significant, with the interaction between proximity (on personal property) and education significant at the $0.90 \%$ interval.

Our regression reveals that a number of these attributes provide utility to respondents. Improved air quality and increased water supply were the most important secondary benefit attributes, with improved air quality having the highest coefficient among them. We hypothesized that the attributes that respondents would use most frequently would have the most utility, and the results appears to support this. Improving air quality may have high utility because of the rising importance of clean air, especially in urban areas (Derkzen et al. 2017). Further, past studies have found that air purification generally enjoys higher preference and willingness to pay (Derkzen et al. 2017; Lera-Lopez et al. 2012). Increased water supply may appeal to homeowners that may see easy applications for retained water in irrigation for their property, as respondents in past studies have placed higher values on GI that can provide water (Miller and Montalto 2019). Habitat creation and reduced energy use had considerably lower coefficients when compared to improved air quality and improved water supply. This may be because these attributes do not provide a high level of personal benefit, as ecosystem services that provide more direct benefits to health and well-being tend to be rated more highly (Derkzen et al. 2017). Further, it could also be a symptom of low levels of familiarity or understanding of GI, which have been observed in the literature (Barnhill and Smardon 2012; Shandas 2015).

Proximity was a major component of the choice experiment and proved significant. Respondents significantly found utility in GI that was within a city block or on their personal property; personal property had one of the highest coefficients in the model (0.348), and was considerably higher than within a block, which was also relatively high. This is a somewhat surprising result, as NIMBYism is a fairly common phenomena in the United States. Further, while literature connecting this phenomenon to GI explicitly is scarce, studies like the one done by Katy and Jari (2016) in Finland found that residents preferred stormwater ponds be sited away from their residences. Given that the least preferred option was within the watershed, and that the most preferred one was on personal property, our results suggest that this NIMBY trend is fading, or simply may not be as strong in this area of the United States. This may be due to changing perceptions, but may also be a result of GI being much smaller and less intrusive than the clean energy generators that NIMBYism is often associated with. Personal property GI had the most utility to respondents; this may reflect homeowners who perceive this as the best way to maximize their benefit while also giving them greater leverage and control over form, function, and maintenance. 
Unsurprisingly, respondents found high utility in GI that has a high level of water retention rather than a low level. This is in line with our hypothesis, as we expected respondents that were interested in GI to want to maximize the utility of their expressed purpose in terms of flood mitigation. While we did not quantify this attribute, the general nature of the analysis suggests that homeowners, when faced with a choice, will prefer the option that gives better flood protection and reduce water flow around their home, which is in line with previous findings (Derkzen et al. 2017). Similarly, cost was found to be significant, and negative, which follows general trends for choice experiment models. As a result, this is fairly commonplace, as respondents can be expected to want to pay the lowest amount possible to maximize their utility.

We generated interactions with the intention of investigating how various attributes interacted with demographic attributes in hopes of revealing some insights as to what factors influence respondent's decisions. Specifically, we interacted variables on gender, income, and education, as we wanted to explore how they could influence CSO and GI policy in New Jersey. Interactions with gender and proximity were significant, namely with proximity within the watershed and on personal property. Our regression found that respondents that identified as female attributed less utility to both of these levels of proximity. This may suggest that females have a higher preference for GI on their property as opposed to their male counterparts, which may reveal outreach opportunities and needs for future policy. Respondents with higher levels of education tended to attribute less utility to GI on personal property. This may potentially be a result of better education on water dynamics and GI utility; while other respondents may want the assurances of seeing and maintaining GI personally, respondents with more education may be content to reap the benefits of infrastructure that they don't interact with. Finally, we found that respondents with higher incomes found higher utility for GI within their watershed. This may be due to a preference to use personal property and the surrounding neighborhood for other uses. These interactions may provide insight during policy creation, as they may be able to target various groups to increase acceptance.

\section{Willingness to pay}

We used a marginal willingness to pay analysis and analyzed the interactions between cost and various attributes on the choice experiment set, to understand which attributes were considered the most valuable in monetary terms. The results can be found in Table 5 .

The results show a fairly wide distribution of effects. In terms of secondary benefits of the GI itself, respondents were willing to pay more for increased water supply and improved air quality. Improved air quality had the highest willingness to pay, with respondents willing to pay an additional $\$ 8.89$ over increased water supply, and over four times more than they would pay for reduced energy use or habitat creation. This confirms our findings from the earlier parameter estimate analysis in Table 3, wherein we found that respondents found significant utility in these attributes; they are willing to pay a premium to receive the benefits. Furthermore, this reflects 
Table 5 Marginal willingness to pay estimates $(95 \%$ confidence intervals)

\begin{tabular}{lccc}
\hline Attribute & \multicolumn{3}{l}{ MNL } \\
\cline { 2 - 4 } & WTP (\$USD) & Lower limit & Upper limit \\
\hline Secondary benefit & & & \\
Improved air quality & 58.60 & 4.483 & 112.716 \\
Increased water supply & 49.71 & -1.465 & 100.884 \\
Reduced energy use & 13.68 & -28.421 & 55.787 \\
Habitat creation & 10.28 & -34.601 & 55.168 \\
Proximity & & & \\
Personal property & 125.97 & 42.125 & 209.806 \\
Within a block & 110.01 & 32.462 & 187.552 \\
Water retention & & & \\
High & 84.90 & 37.777 & 132.027 \\
\hline
\end{tabular}

findings in earlier studies, in which air quality and water supply had high utility, and thus enjoyed a higher willingness to pay (Derkzen et al. 2017; Lera-Lopez et al. 2012).

Though these secondary benefits were valuable, respondents were willing to pay higher premiums for placement than for any of the benefits. Respondents were willing to pay about $\$ 16$ more for GI closer to home as compared to within the block, mirroring our findings in the earlier analysis. However, this constitutes a $\$ 67.37$ increase from the highest secondary benefit and a $\$ 41.07$ increase from the water retention attribute, making it the most valuable attribute by a considerable margin. This may be in an effort to realize more of the benefits, or to have more control in the implementation and maintenance. Respondents were also willing to pay more for retaining high amounts of water and mitigating floods than for any of the secondary benefits, which may suggest that respondents are more concerned with damages from flooding than with any of the problems that the secondary benefits could potentially help mitigate. This conforms to our expectations, as these areas are prone to flooding, and thus residents should be interested in reducing their frequency through mitigation. These findings suggest that GI that focuses on increasing water supply and improving air quality closer to residences may be ideal in term of garnering social capital.

\section{Policy implications}

Taken together, these findings can provide some insight into potential policies. Given the utility of an increased water supply and improved air quality, decision makers may want to prioritize GI that can more effectively provide them, such as rain barrels and bioretention gardens, respectively. Further, the preference for GI closer to respondents' properties may suggest an opportunity for outreach through offering grants or discounts on the installation of GI on personal property or on a neighborhood basis. As there was considerable utility and willingness to pay attached to high levels of runoff mitigation, it will also be important to ensure that 
GI is chosen and sited in such a way to maximize that benefit. Finally, our interactions may reveal useful clues as to how to target outreach by gender, education, and income depending on the desired GI installation.

\section{Conclusions}

GI is an increasingly popular environmental management tool in mitigating the increasing effects of climate change, and has shown increased popularity throughout the United States and abroad. Though it has been proven effective, there remain many questions on the public preferences of its various forms, and how municipalities might best implement their use of GI with public favor. To this end, this study used discrete choice experiment surveys to gauge the perceptions and willingness to pay of New Jersey residents of three major urban cities (Newark, Elizabeth, and Paterson). Surveys were distributed by Qualtrics online in the spring of 2020, eliciting 471 total responses. The data was analyzed in STATA 15 E using conditional logit regression and marginal willingness to pay analyses. The survey results suggests considerable utility for many secondary attributes (air quality, habitat creation, water supply, noise reduction, etc.), with improved air quality and increased water supply as the most preferred benefits. We also found that respondents found more utility in GI fixtures either on their own property or within a block of them, perhaps due to greater perceived benefits or better control over the form and function of the GI in use. Overall, the utility from GI fulfilling its main purpose, namely increasing water infiltration, was significant and high, showing that respondents, while interested in the other benefits to be gained from infrastructure, are significantly invested in preventing flooding using these tools. Our willingness to pay analysis, suggests a direct correlation between utility and willingness to pay, and thus attributes that were preferred in the choice experiment had higher willingness to pay. This information can be valuable to policy makers and municipal governments for designing GI and other flood mitigation policies in New Jersey by informing some of the qualities that residents' value more highly when choosing GI. Ideally, this study may help inform policy by identifying opportunities to garner public support, add social capital, and allocate resources for more effective deployment of GI. This study helps explain trends across populations, and thus can inform environmental policy in similar urbanized areas.

Our study did suffer from some limitations. A key limitation lay in the fact that knowledge of complex issues such as water dynamics and green engineering is generally uncommon, and thus it can be difficult to evaluate the effectiveness of GI. COVID-19 and the ensuing pandemic limited our survey to an online format, as in person surveys were nearly impossible and mail surveys may have been viewed skeptically given unknowns about how the virus spread. However, due to lockdowns and other restrictions, it is possible that the pandemic led to a higher response rate for an online survey. Future study could utilize a mixed method approach, which could richen the dataset and reduce biases that come from only using an online survey. As this study was largely concerned with understanding perceptions with the intention of identifying areas for policy, future study could also use surveys to assess 
various GI programs and policies to predict public response. Further, our analysis focused on a relatively small subset of urban areas by focusing on New Jersey. To date, there are relatively few large GI initiatives in the state. Thus, it could be interesting to use future work to compare attitudes in areas such as these with ones that have seen large scale mobilization of GI initiatives, such as Philadelphia.

Funding The authors gratefully acknowledge the support of the Clean Energy and Sustainability Analytics Center at Montclair State University. This research was partially funded by the National Science Foundation Award 1555123 and U.S. Department of Agriculture National Institute of Food and Agriculture Grant 2012-67009-19742.

Data availability Data available upon reasonable request.

\section{Declarations}

Conflict of interest Authors declare no conflict of interest.

Ethical approval Cayuse IRB-FY19-20-1562.

\section{References}

Abhijith KV, Kumar P, Gallagher J, McNabola A, Baldauf R, Pilla F, Broderick B, Di Sabatino S, Pulvirenti B (2017) Air pollution abatement performances of green infrastructure in open road and built-up street canyon environments - a review. Atmospheric Environ 162:71-86. https://doi.org/10. 1016/j.atmosenv.2017.05.014

Auckland Regional Council (2009) Low Impact Design Versus Conventional Development. Auckland Regional Council. http://www.aucklandcity.govt.nz/council/documents/technicalpublications/ tr2009-045\%20-\%201ow\%20impact\%20design\%20vs\%20conventional\%20development.pdf

Barnhill K, Smardon R (2012) Research article: gaining ground: green infrastructure attitudes and perceptions from stakeholders in Syracuse, New York. Environ Pract 14(1):6-16. https://doi.org/10. $1017 / \mathrm{s} 1466046611000470$

Battelle (2005) Lower Passaic River Restoration Project- Pathway Analysis Report. Battelle, Columbus, OH. https://sharepoint.ourpassaic.org/Public\%20Documents/2005-07-27\%20Passaic\%20PAR-Batte 1le.pdf

Bowen KJ, Lynch Y (2017) The public health benefits of green infrastructure: the potential of economic framing for enhanced decision-making. Curr Opin in Environ Sustain 25:90-95. https://doi.org/10. 1016/j.cosust.2017.08.003

Brokamp C, Beck AF, Muglia L, Ryan P (2017) Combined sewer overflow events and childhood emergency department visits: a case-crossover study. Sci of the Total Environ 607-608:1180-1187. https://doi.org/10.1016/j.scitotenv.2017.07.104

Casadio A, Maglionico M, Bolognesi A, Artina S (2010) Toxicity and pollutant impact analysis in an urban river due to combined sewer overflows loads. Water Sci and Technol 61(1):207-215. https:// doi.org/10.2166/wst.2010.809

Chen J, Liu Y, Gitau MW, Engel BA, Flanagan DC, Harbor JM (2019) Evaluation of the effectiveness of green infrastructure on hydrology and water quality in a combined sewer overflow community. Sci of the Total Environ 665:69-79. https://doi.org/10.1016/j.scitotenv.2019.01.416

Cohen JP, Field R, Tafuri AN, Ports MA (2012) Cost comparison of conventional gray combined sewer overflow control infrastructure versus a green/gray combination. J Irrigation Drain Eng 138(6):534540. https://doi.org/10.1061/(asce)ir.1943-4774.0000432

de Sousa MRC, Montalto FA, Spatari S (2012) Using Life cycle assessment to evaluate green and grey combined sewer overflow control strategies. J Ind Ecol 16(6):901-913. https://doi.org/10.1111/j. 1530-9290.2012.00534.x 
Derkzen ML, van Teeffelen AJA, Verburg PH (2017) Green infrastructure for urban climate adaptation: how do residents' views on climate impacts and green infrastructure shape adaptation preferences? Landsc Urban Plan 157:106-130. https://doi.org/10.1016/j.landurbplan.2016.05.027

Donovan E, Roberts J, Harris M, Finley B (2006) Risk of gastrointestinal disease associated with pathogen exposure in the lower passaic river. Epidemiol. https://doi.org/10.1097/00001648-20061 1001-01348

Econsult Solutions (2016) The economic impact of green city, clean waters: the first five years. Sustainable Business Network of Philadelphia. www.sbnphiladelphia.org/images/uploads/Green\%20City,\% 20Clean $\%$ 20Waters-The\%20First $\% 20$ Five\%20Years.pdf

Fu X, Goddard H, Wang X, Hopton ME (2019) Development of a scenario-based stormwater management planning support system for reducing combined sewer overflows (CSOs). J of Environ Manag 236:571-580. https://doi.org/10.1016/j.jenvman.2018.12.089

Halkos G, Matsiori S (2012) Determinants of willingness to pay for coastal zone quality improvement. The J of Socio-Econ 41(4):391-399. https://doi.org/10.1016/j.socec.2012.04.010

Heng Y, Lu CL, Yu L, Gao Z (2020) The heterogeneous preferences for solar energy policies among US households. Energy Policy 137:111187. https://doi.org/10.1016/j.enpol.2019.111187

Jagai JS, Li Q, Wang S, Messier KP, Wade TJ, Hilborn ED (2015) Extreme precipitation and emergency room visits for gastrointestinal illness in areas with and without combined sewer systems: an analysis of Massachusetts Data, 2003-2007. Environ Health Perspect 123(9):873-879. https://doi.org/10. 1289/ehp. 1408971

Jayasooriya VM, Ng AW (2014) Tools for modeling of stormwater management and economics of green infrastructure practices: a review. Water Air Soil Pollut. https://doi.org/10.1007/s11270-014-2055-1

Lancaster KJ (1976) A new approach to consumer theory. Lecture Notes Econ Math Systems. https://doi. org/10.1007/978-3-642-51565-1_34

Lera-López F, Faulin J, Sánchez M (2012) Determinants of the willingness-to-pay for reducing the environmental impacts of road transportation. Transp Res Part d: Transp Environ 17(3):215-220. https:// doi.org/10.1016/j.trd.2011.11.002

Li C, Peng C, Chiang PC, Cai Y, Wang X, Yang Z (2019) Mechanisms and applications of green infrastructure practices for stormwater control: a review. J Hydrol 568:626-637. https://doi.org/10. 1016/j.jhydrol.2018.10.074

Mangham LJ, Hanson K, McPake B (2008) How to Do (Or Not to Do) ... designing a discrete choice experiment for application in a low-income country. Health Policy and Plan 24(2):151-158. https:// doi.org/10.1093/heapol/czn047

McFadden D, University Of California B. I. U. R. D. (1973) Conditional logit analysis of qualitative choice behavior. Amsterdam University Press

Meng T, Hsu D (2019) Stated preferences for smart green infrastructure in stormwater management. Landsc Urban Plan 187:1-10. https://doi.org/10.1016/j.landurbplan.2019.03.002

Miller SM, Montalto FA (2019) Stakeholder perceptions of the ecosystem services provided by green infrastructure in New York City. Ecosys Serv 37:100928. https://doi.org/10.1016/j.ecoser.2019. 100928

New Jersey Department of Environmental Protection (NJDEP) (2015) Damage Assessment Report on the Effects of Hurricane Sandy on the State of New Jersey's Natural Resources. https://www.nj.gov/dep/ dsr/hurricane-sandy-assessment.pdf.

New Jersey Department of Environmental Protection (2019) CSO Basics. NJDEP, https://www.nj.gov/ dep/dwq/cso-basics.htm.

Nordman EE, Isley E, Isley P, Denning R (2018) Benefit-cost analysis of stormwater green infrastructure practices for grand rapids, Michigan, USA. J of Clean Prod 200:501-510. https://doi.org/10.1016/j. jclepro.2018.07.152

Philadelphia Water Department (2017a) 5 Down, 20 to Go: Celebrating 5 Years of Cleaner Water and Greener Neighborhoods. Philadelphia Water Department, phillywatersheds.org/5Down.

Philadelphia Water Department (2017b) Green City, Clean Waters. Philadelphia Water Department, www.phillywatersheds.org/what_were_doing/documents_and_data/cso_long_term_control_plan.

Salerno F, Gaetano V, Gianni T (2018) Urbanization and climate change impacts on surface water quality: enhancing the resilience by reducing impervious surfaces. Water Res 144:491-502. https://doi. org/10.1016/j.watres.2018.07.058

Sandoval S, Torres A, Pawlowsky-Reusing E, Riechel M, Caradot N (2013) The Evaluation of rainfall influence on combined sewer overflows characteristics: the Berlin case study. Water Sci Technol 68(12):2683-2690. https://doi.org/10.2166/wst.2013.524

\section{SN Social Sciences}

A SPRINGER NATURE journal 
Shandas V (2015) Neighborhood change and the role of environmental stewardship: a case study of green infrastructure for stormwater in the City of Portland, Oregon, USA. Ecol and Soc. https://doi.org/10. 5751/es-07736-200316

Shibata T, Kojima K, Lee SA, Furumai H (2014) Model evaluation of faecal contamination in coastal areas affected by urban rivers receiving combined sewer overflows. Water Sci Technol 70(3):430 436. https://doi.org/10.2166/wst.2014.225

Shr YH, Ready RJ, Orland B, Echols S (2019) How do visual representations influence survey responses? evidence from a choice experiment on landscape attributes of green infrastructure. Ecol Econ 156:375-386. https://doi.org/10.1016/j.ecolecon.2018.10.015

Soriano L, Rubió J (2019) Impacts of combined sewer overflows on surface water bodies. The case study of the Ebro River in Zaragoza City. J Clean Prod 226:1-5. https://doi.org/10.1016/j.jclepro.2019.04. 033

Tsihrintzis VA, Hamid R (1997) Modeling and management of urban stormwater runoff quality: a review. Water Resour Manag 11(2):136-164. https://doi.org/10.1023/A:1007903817943

United States Environmental Protection Agency (USEPA) (2007) Reducing Stormwater Costs through Low Impact Development (LID) Strategies and Practices. EPA. https://www.epa.gov/sites/default/ files/2015-10/documents/2008_01_02_nps_lid_costs07uments_reducingstormwatercosts-2.pdf.

United States Environmental Protection Agency (USEPA) (2012) Perth Amboy to Upgrade Sewer System; Agreement Reached with the EPA to Address Violations of the Clean Water Act Affecting the Raritan River and the Arthur Kill. EPA. http://yosemite.epa.gov/opa/admpress.nsf/6427a6b753 8955c585257359003f0230/452629a43c7ca07285257a150066a2b0!OpenDocument

United States Environmental Protection Agency (USEPA) (2013) Case Studies Analyzing the Economic Benefits of Low Impact Development and Green Infrastructure Programs. EPA 841-R-13-004. https://www.epa.gov/sites/default/files/2015-10/documents/lid-gi-programs_report_8-6-13_combi ned.pdf.

US Census Bureau (2020) QuickFacts from the US Census Bureau. US Census Bureau. http://quickfacts. census.gov/qfd/states/34/3451000.html

Venkataramanan V, Packman AI, Peters DR, Lopez D, McCuskey DJ, McDonald RI, Miller WM, Young SL (2019) A Systematic review of the human health and social well-being outcomes of green infrastructure for stormwater and flood management. J of Environ Manag 246:868-880. https://doi.org/ 10.1016/j.jenvman.2019.05.028

Venkataramanan V, Lopez D, McCuskey DJ, Kiefus D, McDonald RI, Miller WM, Packman AI, Young SL (2020) Knowledge, attitudes, intentions, and behavior related to green infrastructure for flood management: a systematic literature review. Sci of the Total Environ 720:137606. https://doi.org/10. 1016/j.scitotenv.2020.137606

Veronesi M, Chawla F, Maurer M, Lienert J (2013) Climate change and the willingness to pay to reduce ecological and health risks from wastewater flooding in urban centers and the environment. SSRN Electron J. https://doi.org/10.2139/ssrn.2205327

Zhang K, Chui TF (2019) Linking hydrological and bioecological benefits of green infrastructures across spatial scales - a literature review. Sci of the Total Environ 646:1219-1231. https://doi.org/10. 1016/j.scitotenv.2018.07.355

\section{Authors and Affiliations}

\section{Taylor Wieczerak $^{1,3}$ (1) $\cdot$ Pankaj Lal $^{1} \cdot$ Benjamin Witherell $^{2} \cdot$ Sydney Oluoch ${ }^{1}$}

Pankaj Lal

lalp@montclair.edu

Benjamin Witherell

Benjamin.Witherell@bpu.nj.gov

Sydney Oluoch

oluochs1@montclair.edu

1 Department of Earth and Environmental Studies, Montclair State University, Montclair, NJ 07043, USA 
2 New Jersey Board of Public Utilities, 44 S Clinton Ave, Trenton, NJ 08625 , USA

3 Center for Life and Environmental Sciences, Montclair State University, 1 Normal Ave, Montclair, NJ 07043 , USA 